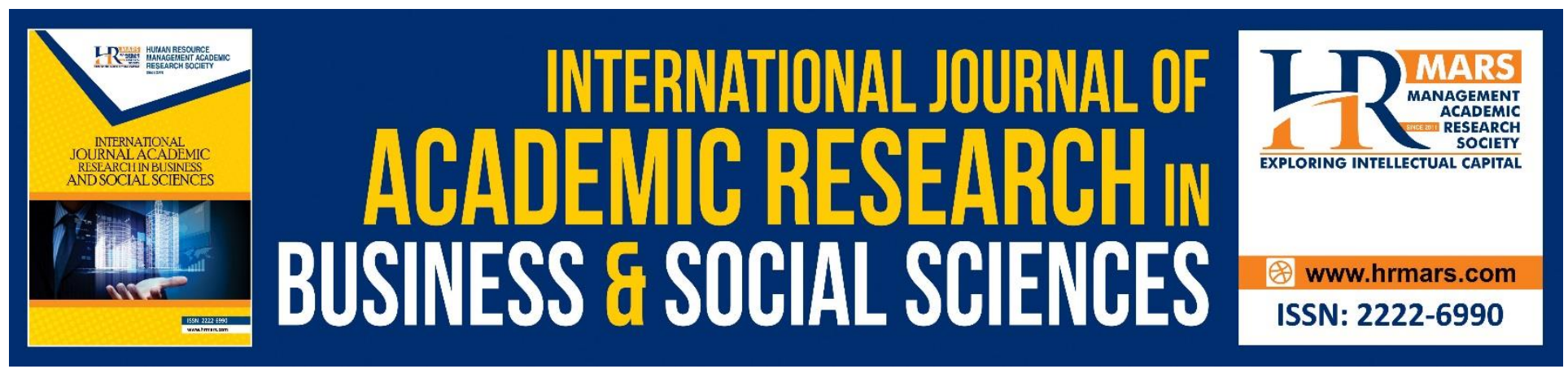

\title{
The Volatility of Individual Securities in Measuring Value at Risk of a Portfolio
}

Farah Azaliney Mohd Amin, Md Nizam Udin, Dina Shafreena Mhd Saiful Anuar, Nur Amirah Mohd Jasni, Nur Syahirah Mahazal

To Link this Article: http://dx.doi.org/10.6007/IJARBSS/v10-i10/7765

DOI:10.6007/IJARBSS/v10-i10/7765

Received: 06 August 2020, Revised: 26 August 2020, Accepted: 19 September 2020

Published Online: 23 October 2020

In-Text Citation: (Amin, et al., 2020)

To Cite this Article: Amin, F. A. M., Udin, M. N., Anuar, D. S. M. S., Jasni, N. A. M., \& Mahazal, N. S. (2020). The Volatility of Individual Securities in Measuring Value at Risk of a Portfolio. International Journal of Academic Research in Business and Social Sciences. 10(10), 504-510.

Copyright: (C) 2020 The Author(s)

Published by Human Resource Management Academic Research Society (www.hrmars.com)

This article is published under the Creative Commons Attribution (CC BY 4.0) license. Anyone may reproduce, distribute, translate and create derivative works of this article (for both commercial and non-commercial purposes), subject to full attribution to the original publication and authors. The full terms of this license may be seen at: http://creativecommons.org/licences/by/4.0/legalcode

Vol. 10, No. 10, 2020, Pg. 504 - 510

http://hrmars.com/index.php/pages/detail/IJARBSS

JOURNAL HOMEPAGE

Full Terms \& Conditions of access and use can be found at http://hrmars.com/index.php/pages/detail/publication-ethics 


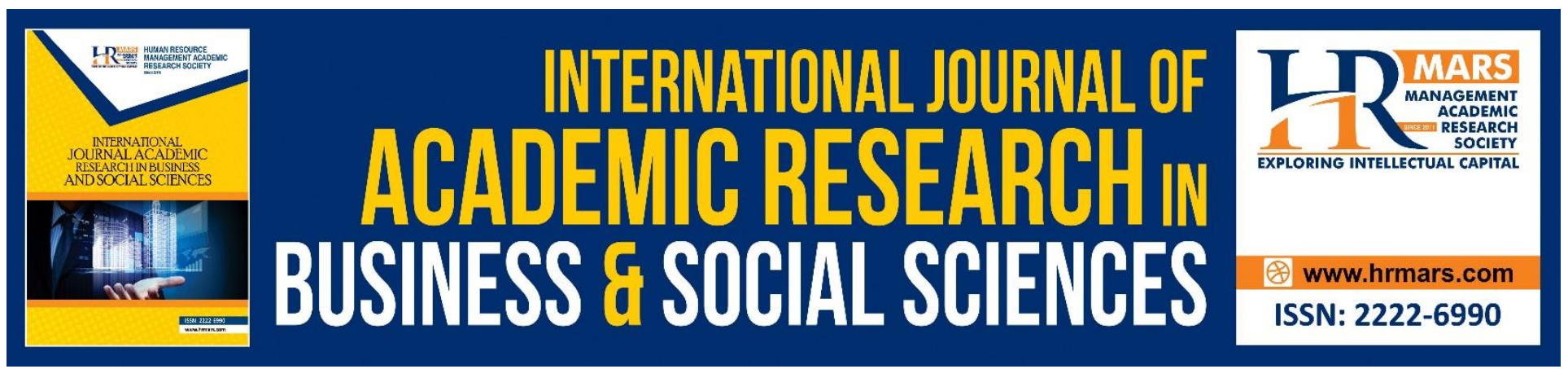

\title{
The Volatility of Individual Securities in Measuring Value at Risk of a Portfolio
}

\author{
Farah Azaliney Mohd Amin, Md Nizam Udin, Dina Shafreena Mhd \\ Saiful Anuar, Nur Amirah Mohd Jasni, Nur Syahirah Mahazal \\ Faculty of Computer and Mathematical Sciences, Universiti Teknologi MARA Cawangan Negeri \\ Sembilan, Kampus Seremban, Malaysia \\ Email: farah525@uitm.edu.my
}

\begin{abstract}
Nowadays, investing in a portfolio of stocks or securities has been one of the most efficient ways for investors to increase wealth. Risk and return of each security are two main criteria to be considered in constructing an optimal portfolio. Previously, market risk is being measured using the standard deviation of changes in prices of the stock is referred to as price volatility. However, the majority of investors fail to relate it with the return of investment. Thus, the Value at Risk (VaR) concept has been successfully introduced to summarise the market risk of a portfolio as one number, for example in Ringgit Malaysia (RM). In this study, there are three main approaches consist of Delta Normal, Historical Simulation and Monte Carlo Simulation to measure monthly VaR for a portfolio of stocks from Sime Darby Sdn Bhd. at 95 and 99\% confidence level. Empirical results show that VaR at $99 \%$ confidence level is higher than $95 \%$. The findings also indicated that property stocks have the highest volatility and can be considered as the riskiest among the securities observed. Finally, risk managers and investors would be in a position to select a better stock portfolio with a known risk measure by employing the concept of VaR.
\end{abstract}

Keywords: Value at Risk, Variance-Covariance, Historical Simulation, Monte Carlo Simulation, Volatility

\section{Introduction}

An investment is a financial term to describe a monetary asset purchased today to generate income in the future. This includes the purchase of bonds, stocks or real-estate properties such as houses, warehouses, factories, etc. However, recent trends indicate that investors tend to invest more in the equity of listed companies on the stock exchange as their passive income (Carpenter \& Petersen, 2002). Eventually, risk management has emerged as a response to increased volatility in global financial markets (Jorion, 2001).

Thus, risk management must include identifying, assessing risk and then responding to them. In the current situation, it is difficult for investors, shareholders and financial managers to determine the total risk of their asset portfolio using standard deviation. In practice when the distribution has 
to be estimated from actual data, the standard deviation is much more robust than VaR measures since its calculation is based on the entire distribution (Kaplanski \& Kroll, 2002). Therefore, this study proposed to employ a well-known and established Value at Risk (VaR) concept in the risk measurement method that is effective in describing the volatility of market risk that exist because of changes in prices of stocks.

\section{Value at Risk Methodologies}

Value at Risk (VaR) measures the worst potential loss of a portfolio under normal market conditions over a specific time interval at a given confidence level. More formally, VaR is modeled with a projected probability distribution for the returns over the defined period. Hence, VaR corresponds to the 1-c lower tail level if $c$ is the selected confidence level (Jorion, 2001). The goal of $\mathrm{VaR}$ is to quantify the investor exposure to market risk in any monetary units (Khindanova et.al, 2001). Although there are numerous approaches to calculate $V a R$, this study will only implement these three main approaches: the Variance-Covariance, Historical Simulation and Monte Carlo Simulation.

\section{Variance-Covariance}

According to Bogdan, Baresa and Ivanovic (2015), Variance Covariance is a parametric approach also known as Delta Normal method. Aniunas, Nedzveckas and Krusinskas (2009) state that the main advantages of using Variance Covariance are because the method is simple and easy to be implemented. Historical data is used to measure statistical parameters such as means, standard deviations and correlations. This approach also applies the normality assumption of returns whereby the future returns on assets are assumed to be normally distributed. According to Hull and White (1998), this is the best method to compute VaR for a portfolio that has linear positions but is strictly not recommended to measure the risk of non-linear instruments, such as options or mortgages. Finally, VaR is computed using the formula given by

$$
\operatorname{VaR}=\alpha \sigma_{P} P_{0}=\alpha \sqrt{W^{T} \Sigma W} P_{0}
$$

where $\alpha$ is the level of significance in a standard normal curve that corresponds to (1-c) if $c$ is the selected confidence level, $\sigma_{P}$ is the standard deviation of the portfolio consist of $W$ is a vector of absolute weight for each stock in the portfolio, $W^{T}$ is its transpose, $\Sigma$ denotes Variance-Covariance matrix and $P_{0}$ is the initial portfolio value.

\section{Historical Simulation}

Historical Simulation is a non-parametric approach that eliminates the need to approximate any statistical parameters such as variance or covariance and does not involve any distributional assumptions. Hence, it can be applied to any market risk exposure and assets as claimed by Corkalo (2011). Also, Hendricks (1997) states that Historical Simulation is the simplest way to determine VaR because it uses the historical data directly: for example daily changes over the last three years. This approach assumed that the past scenario obtained is a good and complete representation of expected future scenarios (Kiohos and Dimopoulos, 2007). Thus, the main weakness of Historical Simulation is the scenarios used in computing VaR are limited to those that occurred in the historical sample (Bohdalova, 2007). Hence, this assumption is inappropriate during periods of high volatility 
INTERNATIONAL JOURNAL OF ACADEMIC RESEARCH IN BUSINESS AND SOCIAL SCIENCES Vol. 10, No. 10, 2020, E-ISSN: 2222-6990 @ 2020 HRMARS

and market turbulence. Finally, by ordering the changes in the portfolio value from worst to best, VaR corresponds to the $1 \%$ lower tail if $99 \%$ is the selected confidence level.

\section{Monte Carlo Simulation}

Monte Carlo Simulation was first invented by the researcher Stanislaw Ulam and John Von Neumann in 1946. Monte Carlo Simulation is a board term for computational algorithms that involve using repeated random samples of parameters or inputs and probability distribution to provide approximate solutions (Suhobokov, 2007). Figure 1 below summarizes the steps to calculate monthly Value at Risk based on the three main methodologies applied in this study.

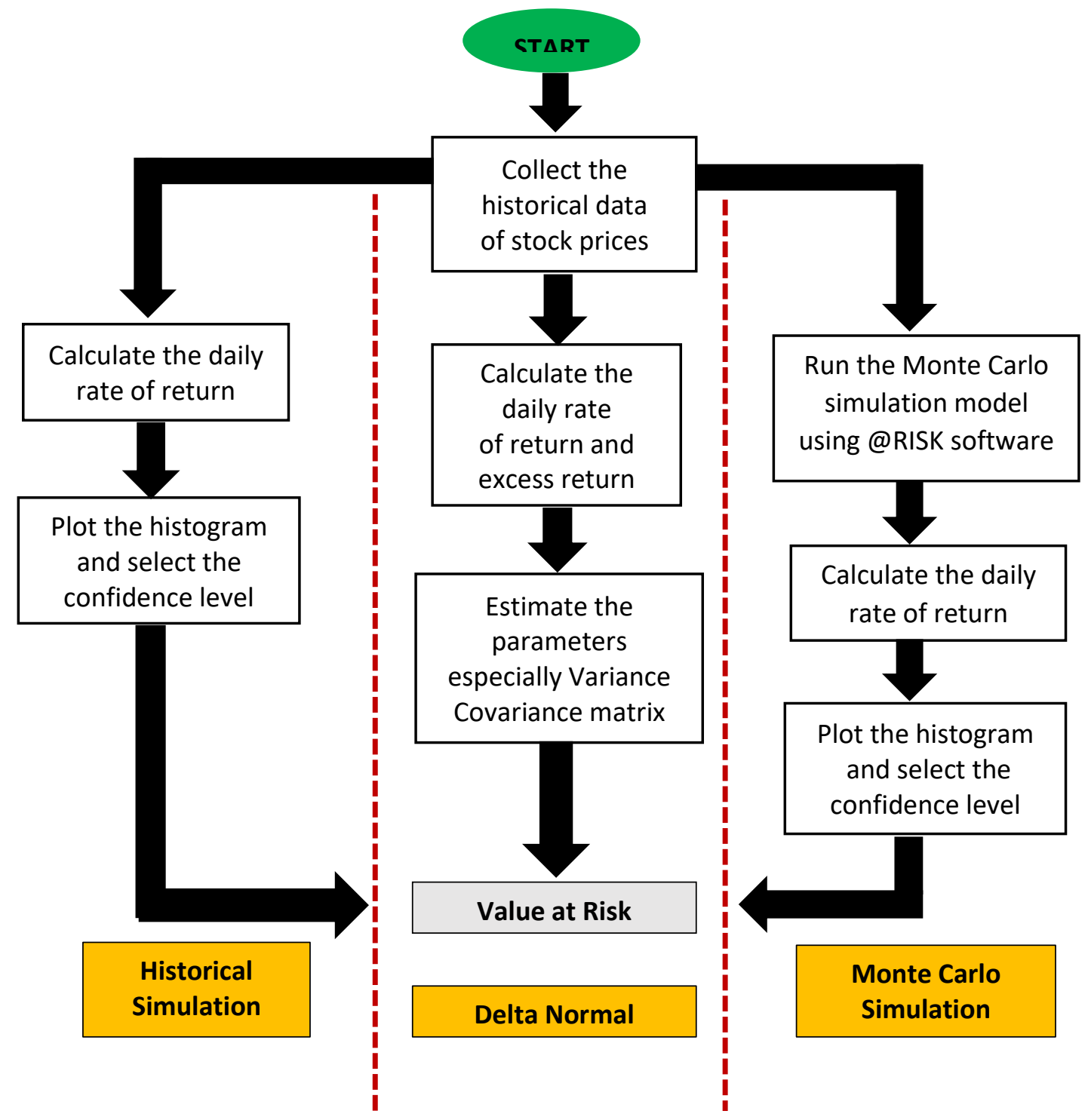

Figure 1: Summary of Comparison between VaR Methodologies

Generally, computing VaR with Monte Carlo, a semi-parametric method is similar to Historical Simulation. The main difference lies in the first step of the algorithm, instead of just using real historical scenarios, this method uses simulation techniques to generate a massive amount of 
INTERNATIONAL JOURNAL OF ACADEMIC RESEARCH IN BUSINESS AND SOCIAL SCIENCES Vol. 10, No. 10, 2020, E-ISSN: 2222-6990 @ 2020 HRMARS

hypothetical changes in the returns over the holding period. This method is far more accurate since it is based on many numbers of iterations done on the same data set (Hsieh and Chou, 2008). Finally, $\mathrm{VaR}$ is determined from this distribution that corresponds to the required level of confidence, for example $99 \%$ as for the Historical Simulation method.

\section{Results and Discussions}

This study attempts to employ Value at Risk concept to estimate the individual market risk of the portfolio in equity investment. For this purpose, daily historical returns for 3 securities of Sime Darby comprising trade, plantation and real estate were collected from January to April 2018 to calculate $\mathrm{VaR}$ at $95 \%$ and $99 \%$ confidence levels. As an example, $99 \%$ means that for about $1 \%$ of the time, an investor could expect to lose more than the number given by the VaR.

\begin{tabular}{|c|c|c|c|c|c|c|}
\hline \multirow{2}{*}{ Month } & \multicolumn{2}{|c|}{ Trading } & \multicolumn{2}{c|}{ Plantation } & \multicolumn{2}{c|}{ Property } \\
\cline { 2 - 7 } & $\mathbf{9 5 \%}$ & $\mathbf{9 9 \%}$ & $\mathbf{9 5 \%}$ & $\mathbf{9 9 \%}$ & $\mathbf{9 5 \%}$ & $\mathbf{9 9 \%}$ \\
\hline $\begin{array}{c}\text { January } \\
2018\end{array}$ & 0.0322 & 0.0456 & 0.0471 & 0.0666 & 0.1027 & 0.1453 \\
\hline $\begin{array}{c}\text { February } \\
2018\end{array}$ & 0.0525 & 0.0743 & 0.0324 & 0.0459 & 0.0781 & 0.1105 \\
\hline March 2018 & 0.0250 & 0.0353 & 0.0217 & 0.0307 & 0.0390 & 0.0551 \\
\hline April 2018 & 0.0243 & 0.0343 & 0.0169 & 0.0239 & 0.0294 & 0.0416 \\
\hline Average & $\mathbf{0 . 0 3 3 5}$ & $\mathbf{0 . 0 4 7 4}$ & $\mathbf{0 . 0 2 9 5}$ & $\mathbf{0 . 0 4 1 8}$ & $\mathbf{0 . 0 6 2 3}$ & $\mathbf{0 . 0 8 8 1}$ \\
\hline
\end{tabular}

Table 1: Summary of Value at Risk for Variance Covariance

Table 1 summarizes the monthly VaR for January until April 2008 using Variance Covariance method. On average, property stocks have the maximum $\mathrm{VaR}$ at $95 \%$ and $99 \%$ confidence level, 0.0623 and 0.0881 respectively. While the plantation stocks have the minimum VaR for both confidence level, 0.0335 and 0.0474 . The results indirectly showed that property is riskier as compared to trading and plantation stocks of Sime Darby.

\begin{tabular}{|c|c|c|c|c|c|c|}
\hline \multirow{2}{*}{ Month } & \multicolumn{2}{|c|}{ Trading } & \multicolumn{2}{c|}{ Plantation } & \multicolumn{2}{c|}{ Property } \\
\cline { 2 - 7 } & $\mathbf{9 5 \%}$ & $\mathbf{9 9 \%}$ & $\mathbf{9 5 \%}$ & $\mathbf{9 9 \%}$ & $\mathbf{9 5 \%}$ & $\mathbf{9 9 \%}$ \\
\hline \multirow{2}{*}{ January 2018 } & 0.035 & 0.048 & 0.037 & 0.057 & 0.045 & 0.122 \\
& 3 & 5 & 3 & 0 & 0 & 5 \\
\hline February & 0.036 & 0.058 & 0.035 & 0.048 & 0.081 & 0.113 \\
2018 & 5 & 0 & 7 & 9 & 3 & 1 \\
\hline \multirow{2}{*}{ March 2018 } & 0.030 & 0.040 & 0.023 & 0.032 & 0.049 & 0.061 \\
& 5 & 8 & 2 & 2 & 7 & 2 \\
\hline \multirow{2}{*}{ April 2018 } & 0.026 & 0.036 & 0.015 & 0.022 & 0.029 & 0.041 \\
& 2 & 3 & 3 & 3 & 0 & 2 \\
\hline \multirow{2}{*}{ Average } & $\mathbf{0 . 0 3 2}$ & $\mathbf{0 . 0 4 5}$ & $\mathbf{0 . 0 2 7}$ & $\mathbf{0 . 0 4 0}$ & $\mathbf{0 . 0 5 1}$ & $\mathbf{0 . 0 8 4}$ \\
& $\mathbf{1}$ & $\mathbf{9}$ & $\mathbf{9}$ & $\mathbf{1}$ & $\mathbf{3}$ & $\mathbf{5}$ \\
\hline
\end{tabular}

Table 2: Summary of Value at Risk for Historical Simulation 
INTERNATIONAL JOURNAL OF ACADEMIC RESEARCH IN BUSINESS AND SOCIAL SCIENCES Vol. 10, No. 10, 2020, E-ISSN: $2222-6990$ @ 2020 HRMARS

Next, Table 2 above showed the result of monthly Value at Risk by employing Historical Simulation method. Using the assumption of the past representing the future, the overall result also indicates that property has the highest volatility and plantation has the lowest volatility incurred for both confidence levels. Moreover, VaR at $99 \%$ is always higher than VaR at $95 \%$ confidence level in the context of stock volatility during the observed period across all the 3 stocks used in this study.

\begin{tabular}{|c|c|c|c|c|c|c|}
\hline \multirow{2}{*}{ Month } & \multicolumn{2}{|c|}{ Trading } & \multicolumn{2}{c|}{ Plantation } & \multicolumn{2}{c|}{ Property } \\
\cline { 2 - 7 } & $\mathbf{9 5 \%}$ & $\mathbf{9 9 \%}$ & $\mathbf{9 5 \%}$ & $\mathbf{9 9 \%}$ & $\mathbf{9 5 \%}$ & $\mathbf{9 9 \%}$ \\
\hline $\begin{array}{c}\text { January } \\
2018\end{array}$ & 0.0162 & 0.0249 & 0.0396 & 0.0461 & 0.0623 & 0.0516 \\
\hline $\begin{array}{c}\text { February } \\
2018\end{array}$ & 0.0271 & 0.0384 & 0.0275 & 0.0213 & 0.0746 & 0.0724 \\
\hline March 2018 & 0.0123 & 0.0573 & 0.0232 & 0.0217 & 0.0655 & 0.0805 \\
\hline April 2018 & 0.0722 & 0.0102 & 0.0255 & 0.0306 & 0.0482 & 0.0568 \\
\hline Average & $\mathbf{0 . 0 3 2 0}$ & $\mathbf{0 . 0 3 2 7}$ & $\mathbf{0 . 0 2 9 0}$ & $\mathbf{0 . 0 2 9 9}$ & $\mathbf{0 . 0 6 2 7}$ & $\mathbf{0 . 0 6 5 3}$ \\
\hline
\end{tabular}

Table 3: Summary of Value at Risk for Monte Carlo Simulation

Finally, Table 3 summarizes the monthly VaR using Monte Carlo Simulation method. The result in Table 3 shows consistency with the previous result obtained by employing Variance-Covariance and Historical Simulation. Overall, property stocks of SIME Darby show the highest VaR and most volatile, while plantation stocks of Sime Darby show minimum VaR indicating the less volatile stocks at both confidence level discussed. The consistency of volatility relative to VaR of three selected stocks from Sime Darby shows that the proposed methods are able to measure market risk, thus making it an alternative to use when investment decisions need to be made.

\section{Conclusion}

Over the past few years, Value at Risk (VaR) has become a standard measure of market risk embraced by banks, trading firms and even non-financial firms. But any risk measure is useful and reliable only if it can be verified by which dimension the risk managers find more important. As an example, if the portfolios without options or mortgages for a short period, Variance Covariance approach does a reasonably good job. While Historical Simulation method provides a good estimate if the VaR is being computed under a normal market condition and there is sufficient historical data set. Thus, in the most general case, Monte Carlo simulations do the best of computing VaR for a nonlinear portfolio over long periods. In conclusion, this study successfully uses the concept of VaR which is easy for investors to understand in measuring and explaining the market risk fluctuations for each stock involved. Based on the VaR value that has been identified, it can certainly help investors in choosing stocks that suit their level of risk. This is because investors know that risk is one of the most important components in making decisions related to their investments. Apart from that, it can help risk managers in evaluating the portfolio as a whole. Finally, risk managers and investors can form an efficient stock portfolio based on known risk analysis using the VaR concept. 
INTERNATIONAL JOURNAL OF ACADEMIC RESEARCH IN BUSINESS AND SOCIAL SCIENCES

Vol. 10, No. 10, 2020, E-ISSN: 2222-6990 @ 2020 HRMARS

\section{References}

Aniunas, P., Nedzveckas, J., \& Krusinskas, R. (2009). Variance-Covariance risk value model for currency market. Engineering Economics, 61(1).

Bogdan, S., Baresa, S., \& Ivanovic, Z. (2015). Estimating risk on the capital market with VaR method. UTMS Journal of Economics, 6(1), 165-175.

Bohdalova, M. (2007). A comparison of Value-at-Risk methods for measurement of the financial risk. Faculty of Management, Comenius University, Bratislava, Slovakia, 10.

Carpenter, R. E., \& Petersen, B. C. (2002). Capital market imperfections, high-tech investment and new equity financing. The Economic Journal, 112(477).

Corkalo, S. (2011). Comparison of Value at Risk approaches on a stock portfolio. Croatian Operational Research Review, 2(1), 81-90.

Hendricks, D. (1997). Evaluation of Value-at-Risk models using historical data. Economic Policy Review, 2(1).

Hsieh, C. S., \& Chou, J. H. (2008). Forecasting Value at Risk (VaR) in the Shanghai Stock Market Using the Hybrid Method. In International Joint conference on e-Commerce, e-Aministration, $e$ Society, and e-Education, 1-16.

Hull, J., \& White, A. (1998). Incorporating volatility updating into the historical simulation method for Value-at-Risk. Journal of Risk, 1(1), 5-19.

Jorion, P. (2001). Value at Risk: The New Benchmark for Managing Financial Risk. NY: McGraw-Hill Professional.

Kaplanski, G., \& Kroll, Y. (2002). VaR risk measures versus traditional risk measures: An analysis and survey. Journal of Risk, 4(3), 1-27.

Karlsson, M., \& Flodman, J. (2011). Value at Risk: A comparison of Value at Risk models during the 2007/2008 financial crisis.

Khindanova, I., Rachev, S., \& Schwartz, E. (2001). Stable modeling of Value at Risk. Mathematical and Computer Modelling, 34(9-11), 1223-1259.

Kiohos, A., \& Dimopoulos, A. (2007). Estimation portfolio VaR with three different methods: financial institution risk management approach. SPOUDAl-Journal of Economics and Business, 54(2), 5983.

Suhobokov, A. (2007). Application of Monte Carlo simulation methods in risk management. Journal of Business Economics and Management, 8(3), 165-168. 